\title{
Ginsenoside compound $K$ exerts antitumour effects in renal cell carcinoma via regulation of ROS and IncRNA THOR
}

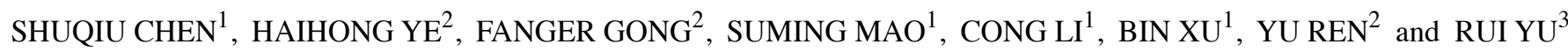 \\ ${ }^{1}$ Department of Urology, Zhongda Hospital, Southeast University, Nanjing, Jiangsu 210009; ${ }^{2}$ Department of Urology, \\ Ningbo Urology and Nephrology Hospital, Ningbo, Zhejiang 315100; ${ }^{3}$ Department of Biochemistry and Molecular Biology, \\ Zhejiang Key Laboratory of Pathophysiology, Medical School, Ningbo University, Ningbo, Zhejiang 315210, P.R. China
}

Received April 19, 2020; Accepted January 7, 2021

DOI: $10.3892 / o r .2021 .7989$

\begin{abstract}
Renal cell carcinoma (RCC) is a common type of kidney cancer that lacks effective therapeutic options. Ginsenoside compound K (CK), an active metabolite of ginsenosides, has been reported to induce apoptosis in various types of cancer cells. However, the effects of CK in RCC remain to be elucidated. Thus, the aim of the present study was to investigate the antitumor effects of CK on RCC cells. The effects of $\mathrm{CK}$ on the proliferation, migration, invasion, cell cycle and apoptosis of RCC cell lines (Caki-1 and 768-O) were investigated using MTT, wound healing, Transwell and flow cytometry assays, respectively. Changes in the expression levels of long non-coding RNAs (lncRNAs) and proteins were measured via reverse transcription-quantitative PCR and western blotting, respectively. Transfections with testis associated oncogenic (THOR) small interfering RNA and pcDNA were performed to knock down and overexpress lncRNA THOR, respectively. It was found that CK could effectively inhibit the proliferation, migration and invasion of RCC cells. CK also induced cell cycle arrest and caspase-dependent apoptosis in RCC cells. Furthermore, the generation of reactive oxygen species and inhibition of the lncRNA THOR played important roles in the antitumour effects of CK in RCC cells. The present data revealed that $\mathrm{CK}$ was a potent antitumour agent against RCC.
\end{abstract}

Correspondence to: Dr Yu Ren, Department of Urology, Ningbo Urology and Nephrology Hospital, 1 Qianhe Road, Ningbo, Zhejiang 315100, P.R. China

E-mail: nbrenyu320@163.com

Dr Rui Yu, Department of Biochemistry and Molecular Biology, Zhejiang Key Laboratory of Pathophysiology, Medical School, Ningbo University, 818 Fenghua Road, Ningbo, Zhejiang 315210, P.R. China

E-mail: yurui.ryu@gmail.com

Key words: renal cell carcinoma, ginsenoside compound $\mathrm{K}$, reactive oxygen species, apoptosis, long non-coding RNA, testis associated oncogenic lncRNA

\section{Introduction}

Renal cell carcinoma ( $\mathrm{RCC}$ ) is a common type of kidney cancer, and >300,000 new cases are diagnosed worldwide each year (1). Currently, surgical resection followed by chemotherapy and radiotherapy are the primary therapeutic treatments for RCC (2). Although great improvement has been made in the diagnosis and treatment of RCC in previous decades, RCC remains one of the most drug-resistant malignancies and a frequent cause of cancer-related deaths (2). Therefore, there is an urgent need to identify novel and effective therapeutic strategies for RCC.

In recent years, antitumour compounds from natural herbs have received increasing attention due to their high efficiency and low toxicity. It was estimated that $>50 \%$ of the small molecular antitumour agents that were developed between 1950 and 2015 originated from natural products or their derivates (3). Ginseng, the root and rhizome of Panax ginseng Meyer, has been widely used as a traditional medicine in East Asia for thousands of years. Mounting evidence has indicated that ginseng has different pharmacological effects on various human diseases (4). In addition, ginseng has also been found to possess anti-aging and antioxidant effects (5). Ginsenosides, a group of various steroidal saponins, are the major bioactive compounds in ginseng, and $>40$ ginsenosides have been identified thus far. Ginsenosides have been found to possess various pharmacological activities, such as neuroprotection, cardioprotection, anti-depressant, anti-inflammatory and antitumour activities (5-7).

Compound K (CK) [20-O- $\beta$-d-glucopyranosyl-20(S)-proto panaxadiol] is a major metabolite of the ginsenosides $\mathrm{Rb} 1, \mathrm{Rb} 2$, $\mathrm{Rc}$ and $\mathrm{Rd}$ that are generated by intestinal bacteria via the multistage cleavage of sugar moieties after the oral administration of ginseng (8). To date, numerous investigations regarding the antitumour activities of CK have been conducted. For example, CK has been found to inhibit the tumorigenic activities of glioma and glioma cells $(9,10)$. CK can also inhibit lung cancer cells via various mechanisms, such as endoplasmic reticulum stress and hypoxia-inducible factor-1 $\alpha$ (HIF-1 $\alpha)$-mediated glucose metabolism pathways $(11,12)$. In addition, $\mathrm{CK}$ also possesses antitumour activities against leukaemia, nasopharyngeal carcinoma and colorectal cancer (13-15). However, no investigation has been conducted concerning the effects of CK on RCC cells. 
In the present study, the antitumour activity of CK was investigated in RCC cells. The results showed that $\mathrm{CK}$ could inhibit the proliferation and metastatic ability of RCC cells. It was also observed that CK could induce cell cycle arrest and apoptosis in RCC cells. The mechanistic studies revealed that CK exerted its antitumour effects at least partly via multiple mechanisms. These data revealed that $\mathrm{CK}$ could have applications as a novel, natural agent against RCC.

\section{Materials and methods}

Cell culture and chemicals. HK-2, Caki-1 and 786-O cells were purchased from the American Type Culture Collection. All cells were cultured in RPMI-1640 medium (Gibco; Thermo Fisher Scientific, Inc.) with $10 \%$ heat-inactivated foetal bovine serum (FBS; HyClone; Cytiva), $100 \mathrm{U} / \mathrm{ml}$ penicillin and $100 \mu \mathrm{g} / \mathrm{ml}$ streptomycin (Sigma-Aldrich; Merck KGaA) at $37^{\circ} \mathrm{C}$ in a humidified $5 \% \mathrm{CO}_{2}$ atmosphere. $\mathrm{CK}$ was purchased from Sichuan WeiKeqi Biological Technology Co., Ltd. Pan-caspase inhibitor z-VAD was obtained from Sigma-Aldrich (Merck KGaA) and was used at a concentration of $10 \mu \mathrm{M}$ at $37^{\circ} \mathrm{C}$. z-VAD was added into the culture medium $0.5 \mathrm{~h}$ prior to the treatment with $\mathrm{CK}$. N-Acetyl-L-cysteine (NAC) was purchased from Sigma-Aldrich (Merck KGaA) and was used at $10 \mu \mathrm{M}$ at $37^{\circ} \mathrm{C}$. NAC was added into the culture medium $0.5 \mathrm{~h}$ prior to the treatment with $\mathrm{CK}$. All other chemicals were obtained from Sigma-Aldrich (Merck KGaA).

Transfection. Small interfering RNA (siRNA) targeting testis associated oncogenic (THOR) (si-THOR), negative control scramble siRNA (si-NC), pcDNA3.1 expressing THOR and empty control were synthesized and obtained from Suzhou GenePharma Co., Ltd. Transfections were performed using Lipofectamine ${ }^{\circledR} 2000$ (Thermo Fisher Scientific, Inc.), according to the manufacturer's protocols. Briefly, cells were seeded into a 6 -well plate at a density of $1 \times 10^{5}$ cells/well. Then, $12 \mathrm{~h}$ later, $20 \mathrm{mM}$ siRNAs and/or $10 \mathrm{ng}$ pcDNA3.1 mixed with $5 \mu$ l Lipofectamine in $200 \mu 1$ Opti-MEM ${ }^{\circledR}$ (Thermo Fisher Scientific, Inc.) were added into each well. At $24 \mathrm{~h}$ after transfection, cells were collected and assayed. The sequences used were as follows: si-THOR sense, 5'-GGUGAACACAAUCGA GCAATT-3' and anti-sense, 5'-UUGCUCGAUUGUGUUCAC CTT-3'; scrambled siRNA sense, 5'-ACGCGUAACGCGGGA AUUUdTdT-3' and antisense 5'-AAAUUCCCGCGUUAC GCGUdTdT-3'; and THOR sense, 5'-CTAATACGACTCACT ATAGGGAGAAGCCGAGTTCGCGCCGCCGGTA-3' and antisense, 5'-AAATATTTGGCTTTCCCCGGCC-3'.

Clonogenic assay. For the colony formation assay, cells were seeded in 6-well plates at a density of 500 cells/well and cultured in complete medium (Thermo Fisher Scientific, Inc.). Two weeks later, the cells were fixed and stained with $0.1 \%$ crystal violet (Beyotime Institute of Biotechnology) for $30 \mathrm{~min}$ at room temperature. The number of visible colonies (>50 cells/colony) was counted using the CKX41-32 inverted microscope (magnification, x100; Olympus Corporation).

Cell viability assay. Cells were seeded into 96-well plates $\left(1 \times 10^{4}\right.$ cells/well). A total of $24 \mathrm{~h}$ after culture, the cells were treated with various doses of CK $(10,20$ or $40 \mu \mathrm{M})$ for different times (24, 48 or 72 h). Then, cells were collected, and cell viability was measured as previously described (16).

Reverse transcription-quantitative $(R T-q) P C R$. Total RNA was extracted from cells using TRIzol ${ }^{\circledR}$ reagent (Thermo Fisher Scientific, Inc.) according to the manufacturer's instructions. The quality and quantity of RNA were measured using a NanoDrop ${ }^{\mathrm{TM}} 2000$ (Thermo Fisher Scientific, Inc.). Total RNA was reverse transcribed into cDNA using the PrimeScript RT Reagent Kit (Takara Biotechnology Co., Ltd.) according to the manufacturer's instructions. RT-qPCR was performed on an Applied Biosystems 7500 Detection System (Applied Biosystems; Thermo Fisher Scientific, Inc.) using SYBR $^{\circledR}$ Premix Ex Taq ${ }^{\mathrm{TM}}$ (Takara Biotechnology Co., Ltd.) according to the manufacturer's instructions. The following primers were used: HOX antisense intergenic RNA forward, 5'-CAGTGGGGAACTCTGACTCG-3' and reverse, 5'-GTG CCTGGTGCTCTCTTACC-3'; double homeobox A pseudogene 8 forward, 5'-AGGATGGAGTCTCGCTGTATTGC-3' and reverse, 5'-GGAGGTTTGTTTTCTTCTTTTTT-3'; small nucleolar RNA host gene 14 forward, 5'-GGGTGTTTACGT AGACCAGAACC-3' and reverse, 5'-CTTCCAAAAGCCTTC TGCCTTAG-3'; colorectal neoplasia differentially expressed forward, 5'-GAGGACGTGCTGGGGCT-3' and reverse, 5'-CTGAGTCCATGTCCCGAATC-3'; growth arrest specific 5 forward, 5'-AGCTGGAAGTTGAAATGG-3' and reverse, 5'-CAAGCCGACTCTCCATACC-3'; THOR forward, 5'-CAA GGTGCTTCTCTCTGGATTT-3' and reverse, 5'-GCCAAA GTCATTTGTTGGGTAT-3'; LOC653786 forward, 5'-CTC TCTGGGCTTGATAGCAT-3' and reverse, 5'-ACCATTTAG CATTAAGGCAGTAG-3'; HEIRCC forward, 5'-ACCTCC AGAACTGTGATCCAAAATG-3' and reverse, 5'-TCTTGC TTGATGCTTTGGTCTG-3'; long intergenic non-protein coding RNA 460 forward, 5'-ACAGCATGAGCCAGGACA TC-3' and reverse, 5'-GAAAGCTGCAACATGCTCCC-3'; SPRY4 intronic transcript 1 forward, 5'-GCTGAGCTGGTG GTTGAAAGGAATC-3' and reverse, 5'-GCTTGGCCCACG ATGACTTGG-3'; PVT1 forward, 5'-GCCCCTTCTATG GGAATCACTA-3' and reverse, 5'-GGGGCAGAGATG AAATCGTAAT-3'; urothelial cancer-associated 1 forward, 5'-CCGCTCGAGAGCGCGTGTGGCGGCCGAGCAC-3'

and reverse, 5'-CGCGGATCCAGACACGAGGCCGGCCAC GCCACG-3'; metastatic renal cell carcinoma-associated transcript 1 forward, 5'-CCTATCCСТTTCTCTAAGAA-3' and reverse, 5'-ACTTCTGCAAAAACGTGCTG-3'; metastasis associated lung adenocarcinoma transcript 1 forward, 5'-AAAGCAAGGTCTCCCCACAAG-3' and reverse, 5'-GGT CTGTGCTAGATCAAAAGGCA-3'; TP73 antisense RNA 1 forward, 5'-CCGGTTTTCCAGTTCTTGCAC-3' and reverse, 5'-GCCTCACAGGGAAACTTCATGC-3'; and GAPDH forward, 5'-TGAAGGTCGGAGTCAACGGATTTGGT-3' and reverse, 5'-CATGTGGGCCATGAGGTCCACCAC-3'. The thermocycling conditions were as follows: $95^{\circ} \mathrm{C}$ for $10 \mathrm{~min}$; followed by 35 cycles of $15 \mathrm{sec}$ at $94^{\circ} \mathrm{C}, 15 \mathrm{sec}$ at $60^{\circ} \mathrm{C}$ and $15 \mathrm{sec}$ at $72^{\circ} \mathrm{C}$; and a final extension at $72^{\circ} \mathrm{C}$ for $10 \mathrm{~min}$. The results were calculated with the $2^{-\Delta \Delta \mathrm{Cq}}$ method (17) and normalized to the expression of GAPDH. All the assays were performed in triplicate. The expression levels are shown as fold-change relative to the corresponding controls, which were defined as 1.0. 
Long non-coding RNA (lncRNA) PCR array. Cells were seeded into 6 -well plates $\left(1 \times 10^{5}\right.$ cells/well $)$ and treated with or without CK $(40 \mu \mathrm{M})$ for $24 \mathrm{~h}$. Total lncRNA were extracted using TRIzol (Thermo Fisher Scientific, Inc.) according to the manufacturer's instructions. Next, the RNAs were sent to Shanghai Biotechnology Corporation for human cancer lncPCR array. A total of 6 reference genes and 97 lncRNAs were included in the array ( $\mathrm{RT}^{2}$ lncRNA PCR Arrays; Qiagen, Inc.). IncRNAs were extracted from various databases, including Ensembl (18), manually curated lncRNA literature sources (search terms, 'IncRNA' and 'cancer'), RefSeq (https://www.ncbi.nlm.nih.gov/refseq/) and UCSC Genome Browser (https://genome.ucsc.edu). Briefly, cDNA was synthesized using the $\mathrm{RT}^{2}$ First Strand Kit (Qiagen $\mathrm{GmbH}$ ). Then, qPCR was performed using the $\mathrm{RT}^{2} \mathrm{SYBR}^{\circledR}$ Green Mastermix (Qiagen $\mathrm{GmbH}$ ). Only one replicate for each sample and one pair of primers for each lncRNA were used for the Human Cancer LncRNA PCR Array. The parameters for qPCR were: $95^{\circ} \mathrm{C}$ for $10 \mathrm{~min} ; 95^{\circ} \mathrm{C}$ for $15 \mathrm{sec}$ and $60^{\circ} \mathrm{C}$ for $1 \mathrm{~min}$ (40 cycles). IncRNA expression was compared using the $2^{-\Delta \Delta \mathrm{Cq}}$ method (17). Differentially expressed lncRNAs with statistical significance (as determined using a two-tailed Student's t-test, $\mathrm{P}<0.05)$ were identified.

Wound healing assay. Caki-1 and 786-O cells were seeded at a density of $1 \times 10^{6}$ cells/well in 6-well plates and cultured in medium with a low concentration of FBS $(5 \%)$. FBS was used in order to reduce cell proliferation risk, cells were cultured in a medium (19). After culture for $24 \mathrm{~h}$ when cells reached $\sim 90 \%$ confluency, they were scratched using a $200-\mu 1$ pipette tip and carefully washed with sterile PBS twice to remove the debris. Then, cells were treated with various doses of CK (10, 20 or $40 \mu \mathrm{M})$ at $37^{\circ} \mathrm{C}$. At different time points $(0$ and $24 \mathrm{~h})$, the images were captured using the CKX41-32 inverted microscope (Olympus) and the results were analysed using ImageJ software (v1.46; National Institutes of Health).

Invasion assay. For the cell invasion analysis, a 24-well Transwell assay plate (Corning Life Sciences) was used. Matrigel (Sigma-Aldrich; Merck KGaA) was diluted with serum-free RPMI-1640 medium (1:3) and used to coat the upper surface of the Transwell chamber at room temperature for $1 \mathrm{~h}$. RCC cells $\left(2 \times 10^{4}\right.$ cells/well $)$ exposed to different treatments were added into the upper chamber with $500 \mu \mathrm{l}$ serum-free RPMI-1640. The lower chamber was filled with $500 \mu \mathrm{l}$ complete medium with $20 \% \mathrm{FBS}$, and cells were cultured for $48 \mathrm{~h}$ at $37^{\circ} \mathrm{C}$. Subsequently, the invasive cells were fixed with methanol and stained with $0.5 \%$ crystal violet (Beyotime Institute of Biotechnology) at room temperature for $1 \mathrm{~h}$. Images of cell invasion were captured under the CKX41-32 inverted microscope (Olympus Corporation).

Cell cycle distribution and apoptosis assay. For cell cycle analysis, cells were collected and washed with 1X PBS after being treated with various doses of CK $(10,20$ or $40 \mu \mathrm{M})$ for $24 \mathrm{~h}$ at $37^{\circ} \mathrm{C}$. The cell pellets were fixed in $70 \%$ cold ethanol for $30 \mathrm{~min}$ at $4^{\circ} \mathrm{C}$. The fixed cells were resuspended in $1 \mathrm{X}$ PBS containing $1 \mathrm{mg} / \mathrm{ml}$ RNase A (Sigma-Aldrich; Merck Cayuga) and incubated for $1 \mathrm{~h}$ at $37^{\circ} \mathrm{C}$, and the cells were stained with $50 \mu \mathrm{g} / \mathrm{ml}$ PI (Sigma-Aldrich; Merck KGaA) for $30 \mathrm{~min}$ at room temperature in the dark. To measure apoptosis, cells were collected and washed with PBS. Then, the pellets were resuspended in 1X Annexin V Binding Buffer (Sigma-Aldrich; Merck $\mathrm{KGaA}$ ) followed by incubation for $5 \mathrm{~min}$ in the dark with $5 \mu \mathrm{l}$ Annexin V-FITC and PI (Sigma-Aldrich; Merck KGaA). Both cell cycle distribution and apoptosis were measured using the BD FACSCanto ${ }^{\mathrm{TM}}$ II flow cytometer (BD Biosciences) and analysed with FlowJo software (v8.8.5; FlowJo LLC).

Measurement of reactive oxygen species (ROS). The generation of ROS was measured by staining with 2',7'-dichlorofluorescin diacetate (DCFHDA; Sigma-Aldrich; Merck KGaA), which is converted into fluorescent 2',7'-dichlorofluorescin (DCF) in the presence of peroxides. Therefore, an increase in DCF fluorescence is an indicator of the presence of ROS. A ROS detection assay kit (cat. no. S0033S; Beyotime Institute of Biotechnology) was used to measure intracellular oxidative stress according to the manufacturer's instructions.

Caspase-3 activity assay. Caspase-3 activity was measured using a colorimetric kit (cat. no. ab252897; Abcam), according to the manufacturer's instructions. Briefly, cells were lysed in the lysis buffer provided by the kit after treatment with various doses of $\mathrm{CK}(10,20$ or $40 \mu \mathrm{M})$ for $24 \mathrm{~h}$ at $37^{\circ} \mathrm{C}$, and Ac-DEVD-pNA was used as the substrate. Then, the absorbance was measured at OD405 with an ELx800 ${ }^{\mathrm{TM}}$ microplate reader (BioTek Instruments, Inc.).

Western blotting. After treatment, cells were collected and lysed in RIPA buffer (Beyotime Institute of Biotechnology). The protein concentrations were measured using a Bradford protein assay kit (Beyotime Institute of Biotechnology). Equal amounts of protein $(20 \mu \mathrm{g})$ were separated via SDS-PAGE on $12 \%$ gel, and separated proteins were subsequently transferred to PVDF membranes (EMD Millipore). After blocking with $5 \%$ skimmed milk for $1 \mathrm{~h}$ at room temperature, the PVDF membranes were incubated with the primary antibodies (Cell Signalling Technology, Inc.) overnight at $4^{\circ} \mathrm{C}$. The following primary antibodies were used: Anti-MMP-2 (cat. no. 40994; 1:1,000), anti-MMP-9 (cat. no. 13667; 1:1,000), anti-N-cadherin (cat. no. 13116; 1:1,000), anti-E-cadherin (cat. no. 14472; 1:1,000), anti-Vimentin (cat. no. 5741; 1:1,000), anti-Bcl-2 (cat. no. 15071; 1:1,000), anti-Bcl-xl (cat. no. 2762; 1:1,000), anti-Bax (cat. no. 2774; 1:1,000), anti-caspase-3 (cat. no. 14220; $1: 1,000)$ and anti-GAPDH (cat. no. 5174; 1:5,000). Then, the membranes were incubated at room temperature for $1 \mathrm{~h}$ with anti-mouse (cat. no. 7076) and anti-rabbit HRP-conjugated secondary antibodies (1:5,000; Cell Signalling Technology, Inc.) and visualized using ECL (Thermo Fisher Scientific, Inc.).

Xenograft models. A total of 24 male BALB/c nude mice (age, 4-6 weeks old; weight, 18-23 g) were randomly divided into the following four groups (6 mice/group): i) Treatment with $0 \mathrm{mg} / \mathrm{kg} \mathrm{CK}$; ii) Treatment with $25 \mathrm{mg} / \mathrm{kg} \mathrm{CK}$; iii) treatment with $50 \mathrm{mg} / \mathrm{kg} \mathrm{CK}$; and iv) Treatment with $75 \mathrm{mg} / \mathrm{kg} \mathrm{CK}$. All mice were kept in housing conditions of $40-70 \%$ humidity in a $12 \mathrm{~h}$ dark/light cycle with free access to food and water at $21-25^{\circ} \mathrm{C}$. $786-\mathrm{O}$ and Caki-1 cells $\left(1 \times 10^{7}\right)$ were suspended in $50 \mu 1$ MEM media mixed with $50 \mu 1$ Matrigel (BD Biosciences) and injected subcutaneously into the right flank of mice under 
anesthetiza with $1.5 \%$ pentobarbital sodium $(60 \mathrm{mg} / \mathrm{kg}$ body weight; intraperitoneal injection). Weight loss exceeding $20 \%$ was considered a humane endpoint. No animals died during the experimental period. When the tumour size reached $\sim 100 \mathrm{~mm}^{3}$, the mice were intravenously injected with various concentrations of CK $(0,25,50$ or $75 \mathrm{mg} / \mathrm{kg})$ for 30 days. The tumour sizes were calculated using a calliper every 3 days, and two perpendicular diameters of each tumour were recorded. At 30 days after implantation, mice were euthanized by $\mathrm{CO}_{2}$ inhalation (15\% displacement) and the death of mice was confirmed when there was a lack of pupil response to light. The tumour volume was measured using the following formula: Volume $=\left(\right.$ width $^{2} \times$ length $) / 2$. The protocol was approved by the Institutional Animal Care and Use Committee of Zhongda Hospital, Southeast University (Nanjing, China). All experiments involving animals were conducted following the Guide for the Care and Use of Laboratory Animals published by the Institute for Laboratory Animal Research (20). Necessary efforts were made to minimize the number of animals and their suffering.

Haematoxylin and eosin $(H \& E)$ staining and immunohistochemistry (IHC). Tumour tissues were fixed with $4 \%$ paraformaldehyde (Sigma-Aldrich; Merck KGaA) overnight at room temperature, and then paraffin embedded tissues were cut into 5- $\mu \mathrm{m}$ thick sections. For $\mathrm{H} \& \mathrm{E}$ staining, the sections were stained with haematoxylin (Sigma-Aldrich; Merck KGaA) for $40 \mathrm{sec}$ and eosin (Sigma-Aldrich; Merck KGaA) for $30 \mathrm{sec}$ at room temperature. For IHC staining, paraffin-embedded sections $(5 \mu \mathrm{m})$ were blocked with $10 \%$ bovine serum albumin (Sigma-Aldrich; Merck KGaA) for $1 \mathrm{~h}$ at room temperature, post-hybridized slides were incubated with anti-Ki-67 antibody (cat. no. ab15580; 1:500; Abcam) overnight at $4^{\circ} \mathrm{C}$. Then, slides were washed three times with $0.01 \mathrm{M}$ PBS for $10 \mathrm{~min}$ at room temperature. The slides were incubated with HRP-conjugated rabbit anti-mouse (cat. no. ab7076; 1:1,000; Abcam) secondary antibody for $1 \mathrm{~h}$ at room temperature, and then washed three times for 10 min with $0.01 \mathrm{M}$ PBS. Colour development was conducted using a DAB kit (cat. no. ab64238; Abcam), according to the manufacturer's instructions. The images were visualized using a light fluorescence Olympus BX40 microscope (Olympus Corporation).

Statistical analysis. Statistical analysis was performed using SPSS software v11.2 (SPSS, Inc.). All experiments were repeated at least three times and the data are expressed as the mean \pm SD. Differences among groups were analysed using one-way ANOVA followed by Tukey's post hoc test. $\mathrm{P}<0.05$ was considered to indicate a statistically significant difference.

\section{Results}

$C K$ inhibits the viability of RCC cells. First, the effects of CK on the viability of RCC cells were investigated. Both Caki-1 and 786-O cells are well-established RCC cell lines (21). However, 786-O cells are defective in von Hippel-Lindau disease tumour suppressor (VHL) expression and have altered HIF and VEGF pathways (21). By contrast, Caki-1 cells harbour wild-type VHL and exhibit normal expression of VEGF (21). As shown in Fig. 1A, the MTT assay showed that the viability of Caki-1 and 786-O cells was significantly inhibited by CK in a time- and dose-dependent manner. Moreover, colony formation assays also indicated that the viability of Caki-1 and 786-O cells was significantly suppressed (Fig. 1B). These results suggested the antitumour potential of $\mathrm{CK}$ in RCC cells.

CK inhibits the migration and invasion of RCC cells and induces cell cycle arrest. It is commonly known that migration and invasion are essential steps in the metastatic behaviour of cancer cells. Thus, it was next investigated whether CK could affect the mobility of RCC cells, and wound healing and Transwell invasion assays were performed after treatment with various doses of CK for $48 \mathrm{~h}$. As indicated in Fig. 2A and B, CK treatment inhibited the migration and invasion of both Caki-1 and 786-O cells in a dose-dependent manner. To further analyse the inhibitory effects of CK on the migration and invasion of RCC cells, the expression of cell motility-related proteins were measured via western blotting. As shown in Fig. $2 \mathrm{C}$, treatment with $\mathrm{CK}$ led to the downregulation of MMP-2, MMP-9, Vimentin and $\mathrm{N}$-cadherin, and the upregulation of E-cadherin in both RCC cell lines. Moreover, the effect of CK on the cell cycle distribution of RCC cells was also examined by PI staining. CK treatment led to cell cycle arrest at the G2/M phase in RCC cells in a dose-dependent manner (Fig. 2D). Taken together, these data suggested that $\mathrm{CK}$ repressed migration and invasion and induced cell cycle arrest at the G2/M phase in RCC cells.

CK induces RCC cell apoptosis in a caspase-dependent manner. Next, an Annexin V-FITC staining assay was performed to examine whether $\mathrm{CK}$ could induce RCC cell apoptosis. As shown in Fig. 3A, treatment of Caki-1 and 786-O cells with different doses of $\mathrm{CK}$ resulted in increased apoptosis in a dose-dependent manner. To further confirm the apoptosis-inducing effects of $\mathrm{CK}$, the expression levels of apoptosis-related proteins in RCC cells were measured via western blotting after incubation with various doses of $\mathrm{CK}$ for 48 h. As indicated in Fig. 3B, a dose-dependent decrease in anti-apoptotic proteins, $\mathrm{Bcl}-2$ and $\mathrm{Bcl}-\mathrm{xl}$, and an increase in pro-apoptotic protein Bax were observed in RCC cells after treatment with $\mathrm{CK}$. CK treatment also led to an increase in cleaved caspase-3 (Fig. 3B). In addition, the caspase-3 activity assay also revealed that the activity of caspase- 3 was increased in a dose-dependent manner after treatment with CK (Fig. 3C). Furthermore, the pan-caspase inhibitor z-VAD could repress the CK-induced apoptosis of RCC cells (Fig. 3D). Collectively, these data suggested that $\mathrm{CK}$ induced apoptosis in a caspase-dependent manner in RCC cells.

CK treatment led to the generation of ROS in RCC cells. Previous studies have indicated that $\mathrm{CK}$ could trigger oxidative stress in various cancer cells and tumour models $(22,23)$. Therefore, the present study investigated whether CK treatment could lead to the accumulation of ROS in RCC cells. As shown in Fig. 4A, a dose-dependent increase in ROS was detected in both RCC cell lines after treatment with CK for $24 \mathrm{~h}$. Notably, the ROS scavenger NAC significantly prevented the accumulation of ROS after treatment with CK in RCC cells (Fig. 4A). The MTT assay revealed that the inhibitory effects of CK on the viability of RCC cells could be blocked by NAC (Fig. 4B). In addition, NAC also repressed the CK-induced inhibition 

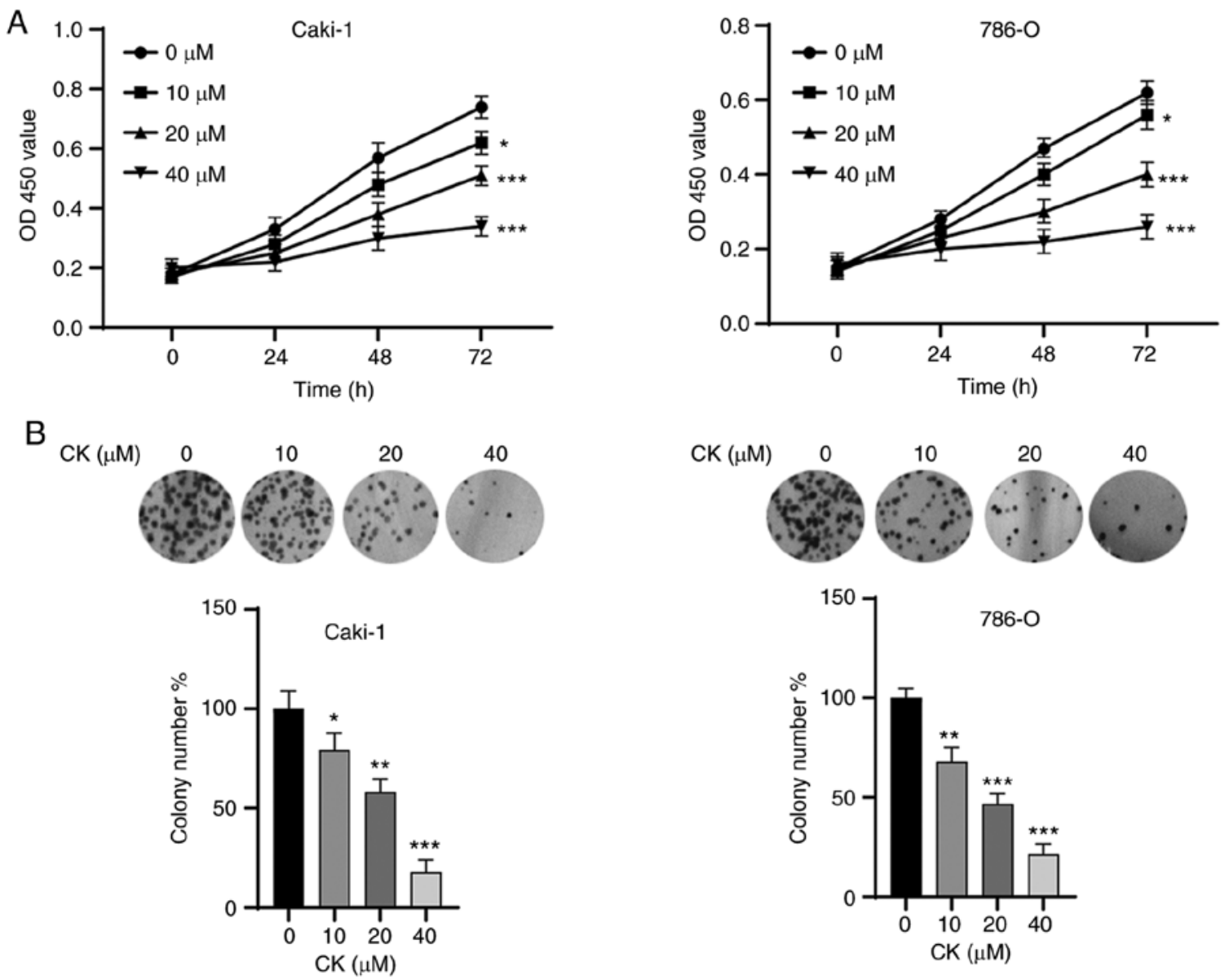

Figure 1.CK inhibits the proliferation of RCC cells. (A) The viability of Caki-1 and 786-O cells was measured via an MTT assay after exposure to various doses of $\mathrm{CK}$ for different times. (B) A colony formation assay was performed to measure the proliferative activity of RCC cells after treatment with various doses of CK. The data are presented as the mean $\pm \mathrm{SD}$ of at least three independent experiments. ${ }^{*} \mathrm{P}<0.05,{ }^{* *} \mathrm{P}<0.01$ and ${ }^{* * * *} \mathrm{P}<0.001$ vs. control group. CK, ginsenoside compound $\mathrm{K}$; RCC, renal cell carcinoma.

of migration and invasion in RCC cells (Fig. 4C and D). Furthermore, the CK-induced apoptosis could also be blocked by NAC in RCC cells (Fig. 4E-G). Taken together, these data suggested that the generation of ROS played an essential role in the antitumour activity of $\mathrm{CK}$ in RCC cells.

IncRNA THOR is downregulated in CK-treated RCC cells. lncRNAs are commonly known to promote tumorigenesis in various cancers, including RCC. To investigate whether any lncRNAs participated in the antitumour activity of CK in RCC cells, the $\mathrm{RT}^{2}$ IncRNA PCR Array system was used. The expression profiles of $25 \mathrm{RCC}$-related lncRNAs were analysed in HK-2, Caki-1 and 786-O cells, and 15 lncRNAs were found to be significantly upregulated in RCC cells compared with normal cells (Fig. 5A). Among these 15 lncRNAs, THOR was the most significantly upregulated in both Caki-1 and 786-O cells (Fig. 5A). To further confirm this finding, the expression levels of 15 lncRNAs in the presence or absence of CK were analysed in Caki-1 and 786-O cells. As indicated in Fig. 5B, the expression of THOR could be significantly inhibited by treatment with CK in both RCC cell lines (Fig. 5B). Taken together, these findings suggested that THOR, the IncRNA exhibiting the greatest reduction after CK treatment, may participate in the antitumour effects of CK. Hence, THOR was chosen for further study in the following experiments.
Silencing of THOR inhibits the oncogenesis of RCC cells. To test whether the effect of $\mathrm{CK}$ on RCC cells might be mediated by THOR, the functions of THOR in RCC cells were studied. RCC cells were transfected with siRNAs, and satisfactory transfection efficiency was achieved $48 \mathrm{~h}$ after transfection (Fig. 6A). The MTT assay showed that knockdown of THOR markedly significantly the viability of both RCC cell lines (Fig. 6B). In addition, wound healing and Transwell assays showed that the knockdown of THOR significantly repressed the migration and invasion of RCC cells (Fig. 6C). Furthermore, the silencing of THOR also induced the apoptosis of RCC cells (Fig. 6D). The anti-apoptotic Bcl-2 protein was downregulated and cleaved caspase-3 was increased after the silencing of THOR in RCC cells (Fig. 6E). Furthermore, silencing of THOR also induced cell cycle arrest at the G2/M phase in RCC cells (Fig. 6F). These data revealed that downregulation of THOR triggered effects on RCC cells similar to those of CK, suggesting that CK might exert its function by targeting THOR.

CK exerts its function in RCC cells at least partially by targeting THOR. To further investigate the role of THOR in the antitumour functions of $\mathrm{CK}$, rescue experiments were conducted. RCC cells were transfected with pcDNA3.1 THOR, which significantly upregulated the expression of THOR (Fig. 7A). The MTT assay revealed that the inhibitory 
A
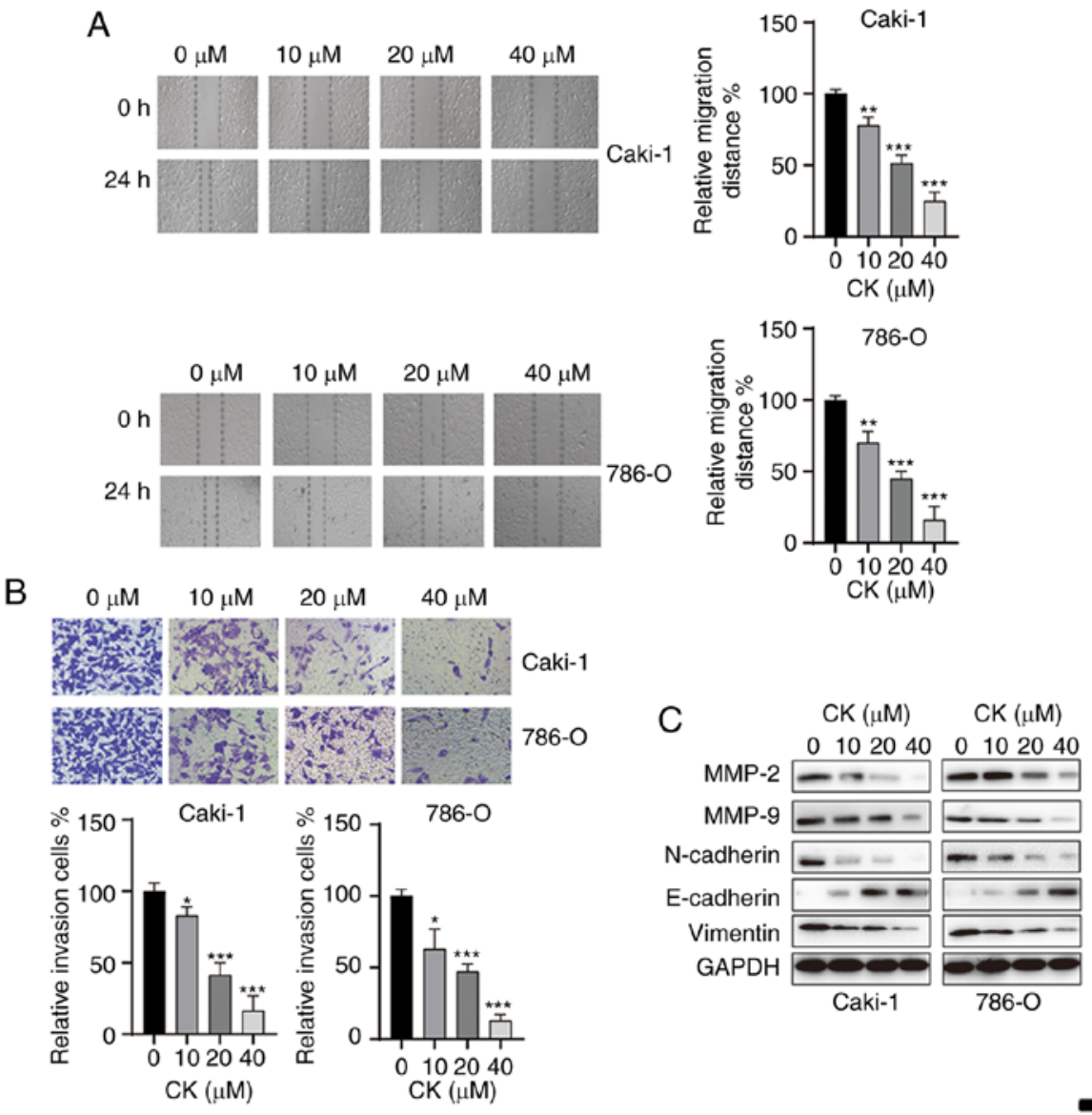

$\mathrm{D}$
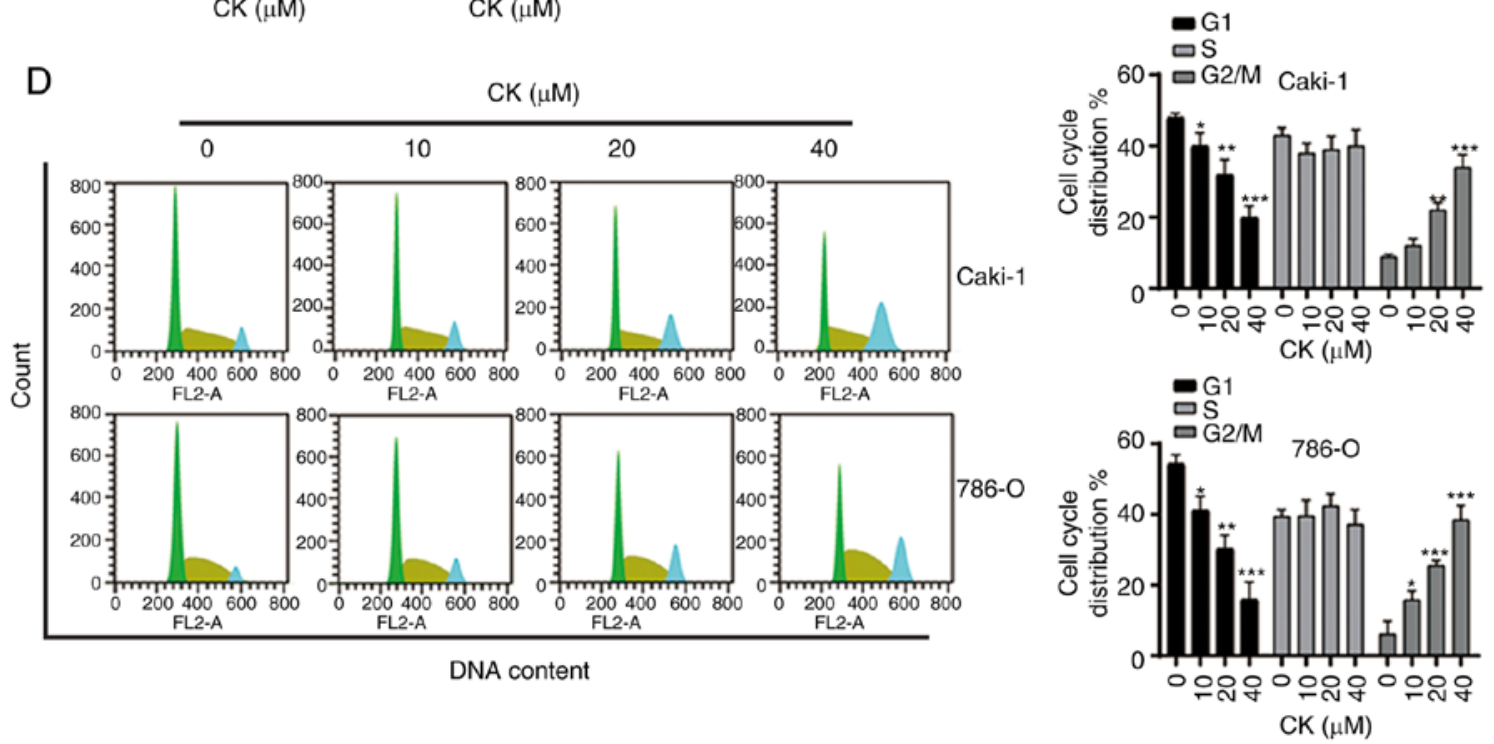

Figure 2. CK inhibits the migration and invasion of RCC cells and induces cell cycle arrest. (A) Wound healing assays were performed to measure the effects of CK on the migration of RCC cells. (B) Transwell invasion assays were performed to measure the effects of CK on the invasion of RCC cells. (C) Cells were treated with different doses of $\mathrm{CK}$ for $24 \mathrm{~h}$, and the total cellular lysates were subjected to western blot analysis with the indicated antibodies. (D) Cells were treated with different doses of $\mathrm{CK}$ for $24 \mathrm{~h}$, and cell cycle distribution was assayed by PI staining and flow cytometry analysis. The data are presented as the mean \pm SD of at least three independent experiments. ${ }^{*} \mathrm{P}<0.05,{ }^{* *} \mathrm{P}<0.01$ and ${ }^{* * *} \mathrm{P}<0.001$ vs. control group. $\mathrm{CK}$, ginsenoside compound $\mathrm{K}$; RCC, renal cell carcinoma.

effects of CK on the viability of RCC cells could be blocked by the overexpression of THOR (Fig. 7B). In addition, wound healing and Transwell invasion assays showed that the effects of CK on RCC cell migration and invasion could be reversed after the overexpression of THOR (Fig. 7C). The apoptosis-inducing effects of $\mathrm{CK}$ on RCC cells were also blocked by the overexpression of THOR (Fig. 7D and E). Furthermore, the CK-mediated cell cycle arrest at the G2/M phase was also reversed by increased THOR expression (Fig. 7F). Taken together, these data suggested that CK exerted its antitumour effects at least partially by targeting THOR.

CK inhibits tumorigenesis in nude mice. Finally, the antitumour activity of $\mathrm{CK}$ was evaluated in male BALB/c mice harbouring established RCC xenografts. The mice were randomized into four groups $(0,25,50$ or $75 \mathrm{mg} / \mathrm{kg})$ and treated with CK every 

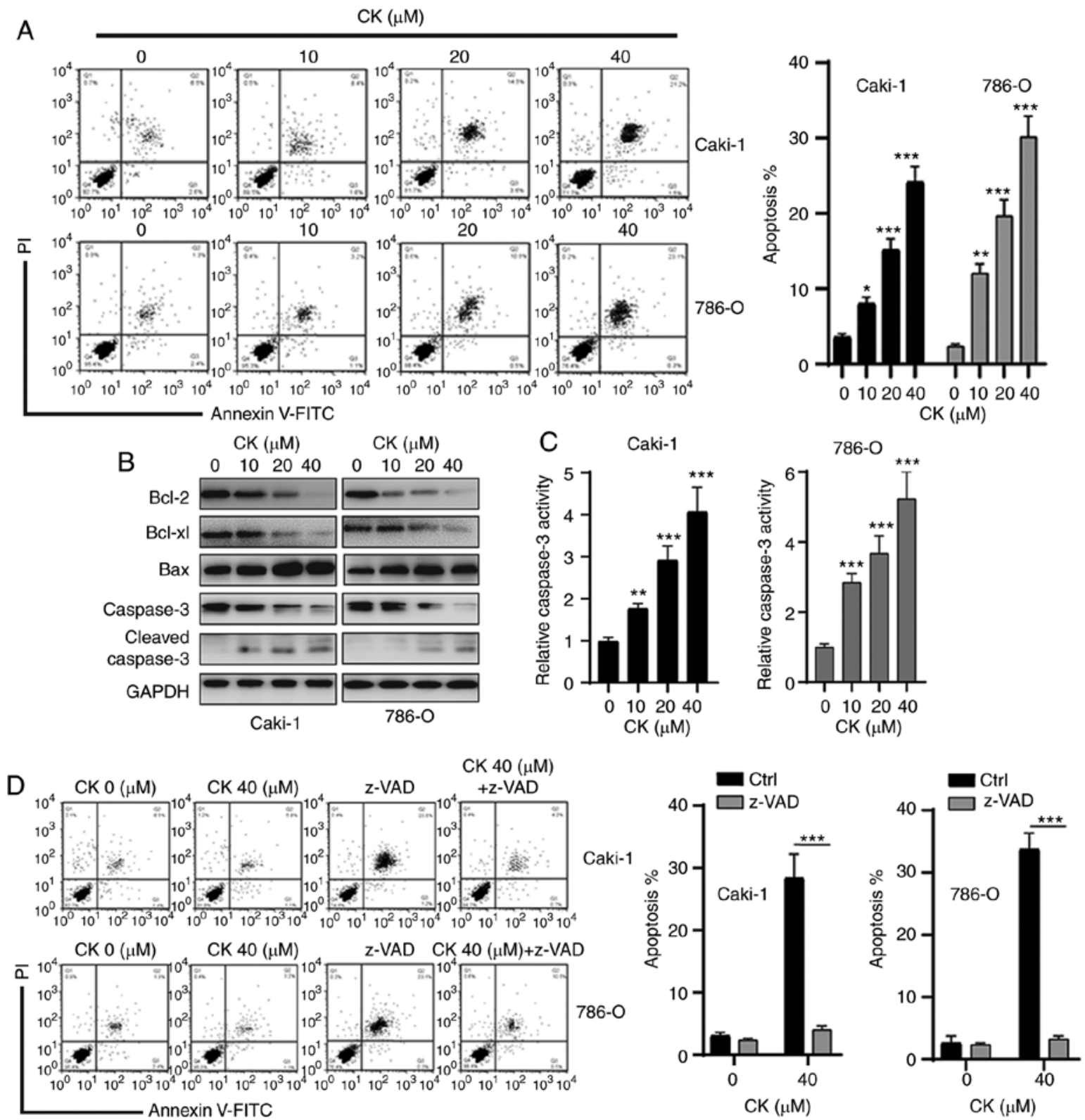

Figure 3. CK induces caspase-dependent apoptosis of renal cell carcinoma cells. (A) Cells were treated with different doses of CK for $24 \mathrm{~h}$, and cellular apoptosis was measured. (B) After incubation with different doses of CK, the expression levels of apoptosis-related proteins were measured via western blotting. (C) Cells were treated with different doses of CK for $12 \mathrm{~h}$, and caspase-3 activity was measured. (D) Cells were treated with CK $(40 \mu \mathrm{M})$ with or without z-VAD $(10 \mu \mathrm{M})$ for $24 \mathrm{~h}$, and cellular apoptosis was measured. The data are presented as the mean $\pm \mathrm{SD}$ of at least three independent experiments. "P<0.05, ${ }^{* *} \mathrm{P}<0.01$ and ${ }^{* * *} \mathrm{P}<0.001$ vs. control group. CK, ginsenoside compound $\mathrm{K}$.

3 days. As shown in Fig. 8A, the mice treated with CK exhibited a significant reduction in tumour size. Notably, the mice tolerated all of the treatments, and no obvious differences in body weight were observed, suggesting that $\mathrm{CK}$ was well tolerated (Fig. 8B). Further study showed that $\mathrm{CK}$ treatment inhibited the expression of Ki-67 in a dose-dependent manner in vivo (Fig. 8C). The western blotting results also confirmed that treatment with $\mathrm{CK}$ induced the cleavage of caspase- 3 in a dose-dependent manner in vivo (Fig. 8D). Taken together, these data indicated that CK inhibited the growth of RCC cells in vivo.

\section{Discussion}

In the current study, it was shown that CK, a metabolite of protopanaxadiol-type ginsenosides produced by gut microbiota, inhibited the oncogenesis of RCC cells via multiple mechanisms in vitro. Ginseng, which is derived from the root of $P$. ginseng Meyer, has been used for the treatment of malignant diseases in Eastern Asia for thousands of years. However, the effects of this herb are hindered by oral administration because it is not easily absorbed by the body (24). By contrast, CK, a ginsenoside metabolite of ginseng, was found to be more easily absorbed by the metabolic system (25). A number of reports have studied the inhibitory effects of CK on various cancers, such as lung cancer, breast cancer, glioma, liver cancer and colon cancer $(10,11,26-28)$. Consistent with previous studies, the present study demonstrated that $\mathrm{CK}$ inhibited the growth of two RCC cell lines (Caki-1 and 786-O) in a dose- and time-dependent manner. Clonogenic, migration and Transwell invasion assays also confirmed the inhibitory 

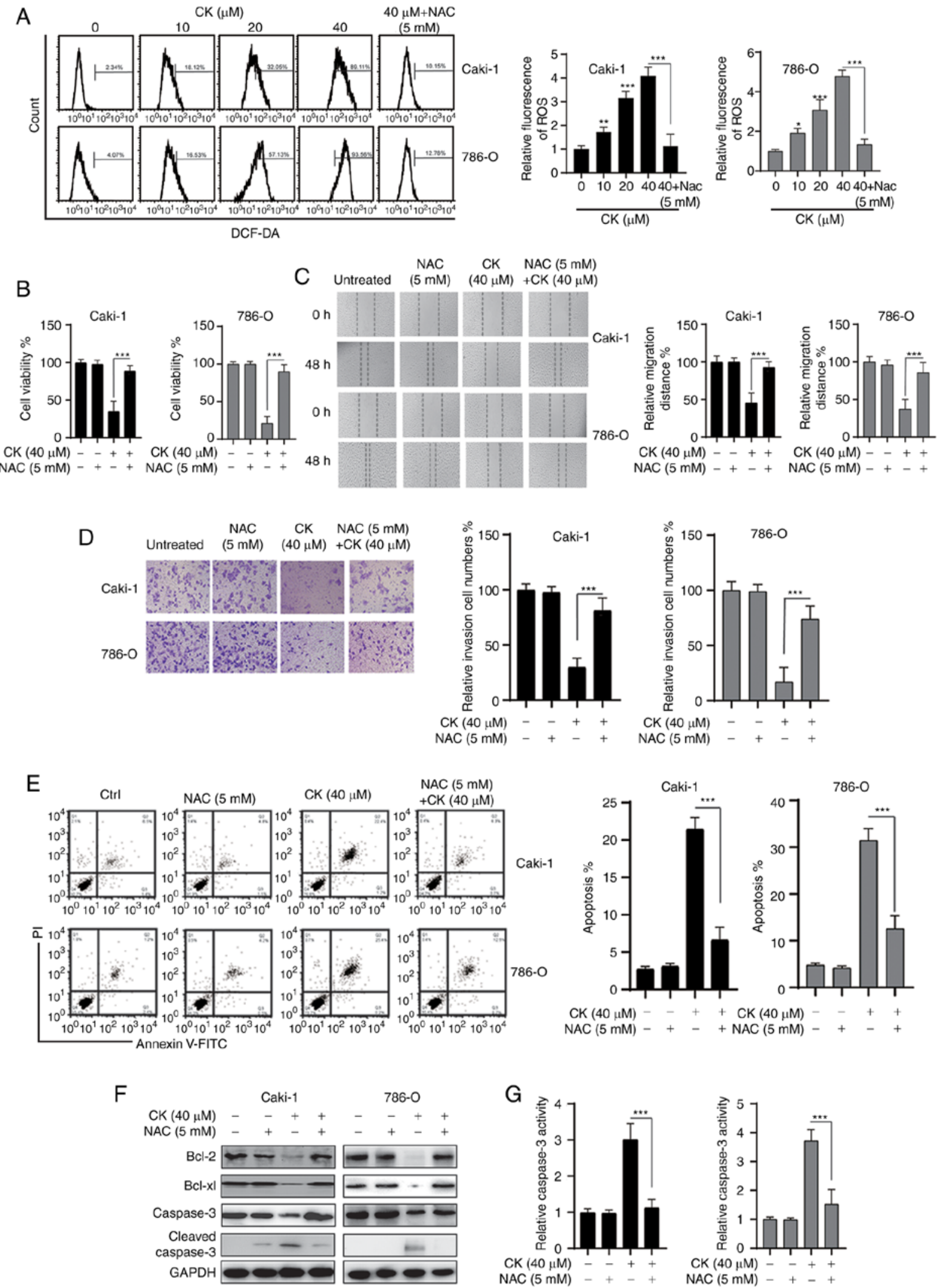

Figure 4. CK treatment leads to the generation of ROS in renal cell carcinoma cells. (A) Intracellular ROS levels were measured by flow cytometry. (B) Cell viability was measured via an MTT assay. (C) Cell migration was measured by a wound healing assay. (D) Cell invasion was measured via a Transwell invasion assay. (E) Cellular apoptosis was measured. (F) The indicated proteins were measured via western blotting. (G) Caspase-3 activity was analysed. The data are presented as the mean $\pm \mathrm{SD}$ of at least three independent experiments. ${ }^{*} \mathrm{P}<0.05,{ }^{* *} \mathrm{P}<0.01$ and ${ }^{* * * *} \mathrm{P}<0.001$ vs. control group or as indicated. CK, ginsenoside compound K; ROS, reactive oxygen species.

effect of CK on RCC cells. These findings suggested that CK may have potential as a potent therapeutic agent for RCC.
Next, the molecular mechanisms of the antitumour effects of CK were systematically investigated. Mounting evidence 


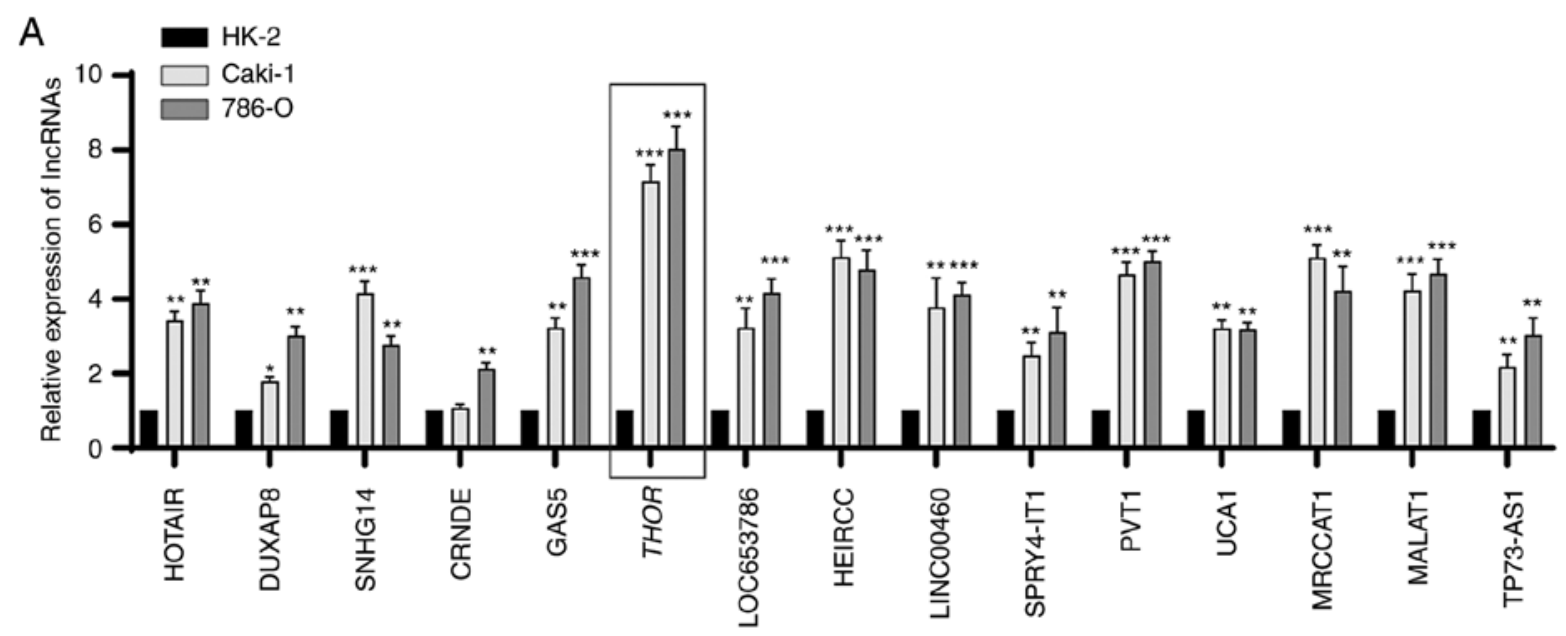

B

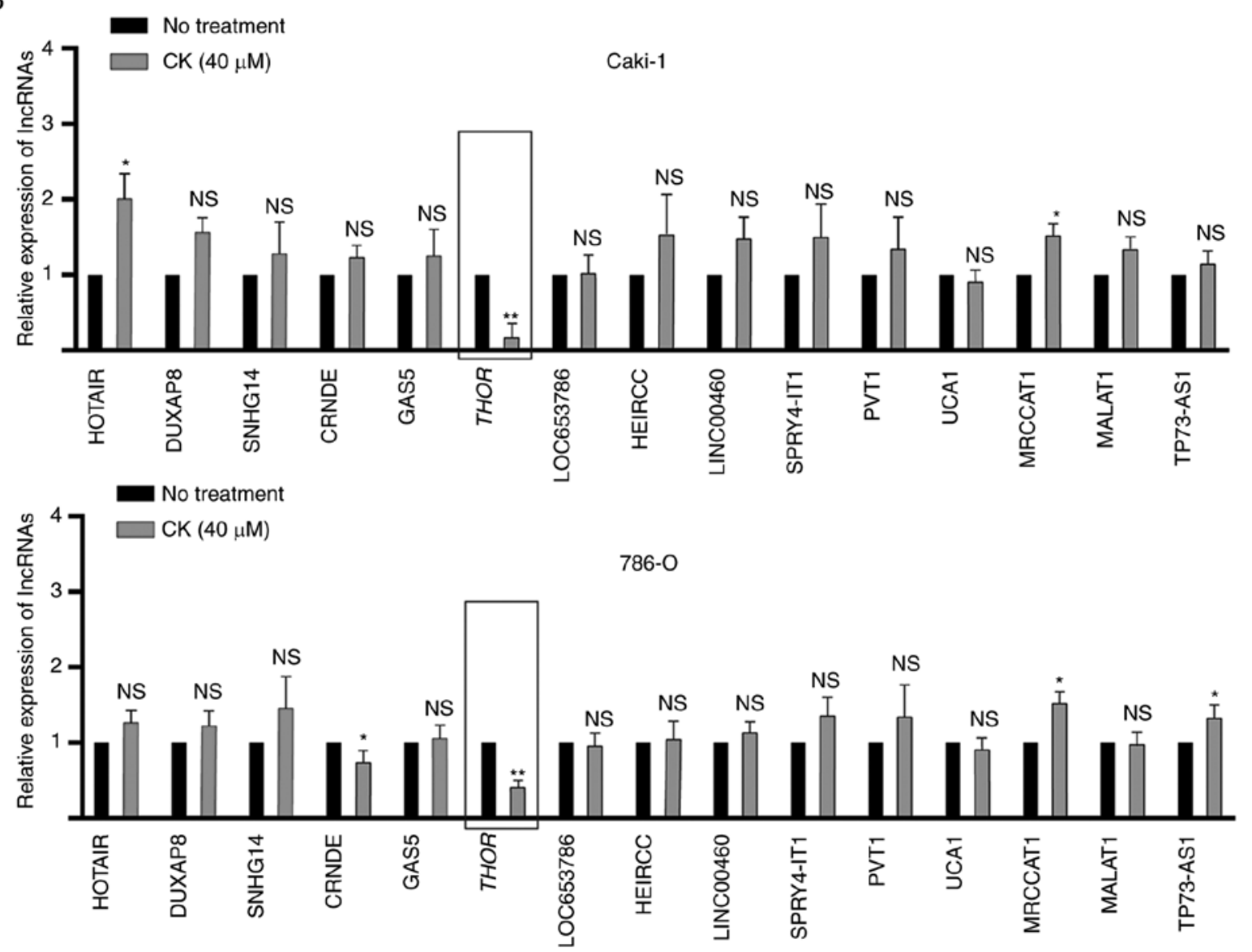

Figure 5. IncRNA THOR is downregulated in RCC cells after exposure to CK. (A) Expression of 15 lncRNAs in HK-2, Caki-1 and 786-O cells. (B) Expression levels of 15 lncRNAs in RCC cells before or after treatment with CK $(40 \mu \mathrm{M})$. The data are presented as the mean \pm SD of at least three independent experiments. ${ }^{*} \mathrm{P}<0.05,{ }^{* * *} \mathrm{P}<0.01$ and ${ }^{* * * *} \mathrm{P}<0.001$ vs. control group. NS, not significant; IncRNA, long non-coding RNA; CK, ginsenoside compound K; RCC, renal cell carcinoma; THOR, testis associated oncogenic.

has indicated that tumour recurrence and metastasis are major obstacles in the treatment of cancer. Epithelial to mesenchymal transition (EMT) is a biological process that is often activated during cancer invasion and metastasis (29). In the present study, $\mathrm{CK}$ treatment led to the downregulation of the mesenchymal markers $\mathrm{N}$-cadherin and Vimentin and the upregulation of the epithelial marker E-cadherin. These data suggested that $\mathrm{CK}$ treatment inhibited EMT in RCC cells. This finding is consistent with a previous study that found that CK inhibited EMT in breast cancer (28). Targeting EMT also plays a critical role in the response of RCC to chemo- and radiotherapies (30). It would be useful to test the effects of CK combined with other therapeutics on RCC.

Various agents mainly exert their antitumour effects by inducing apoptosis. Similar to previous studies, CK was also found to induce apoptosis in RCC cells $(13,22)$. Apoptosis can be triggered via two pathways, namely, the extrinsic and intrinsic pathways (16). The process of apoptosis is subject to regulation by various proteins, such as Bcl-2 family members, mitochondrial proteins and caspases (31). In the present study, 

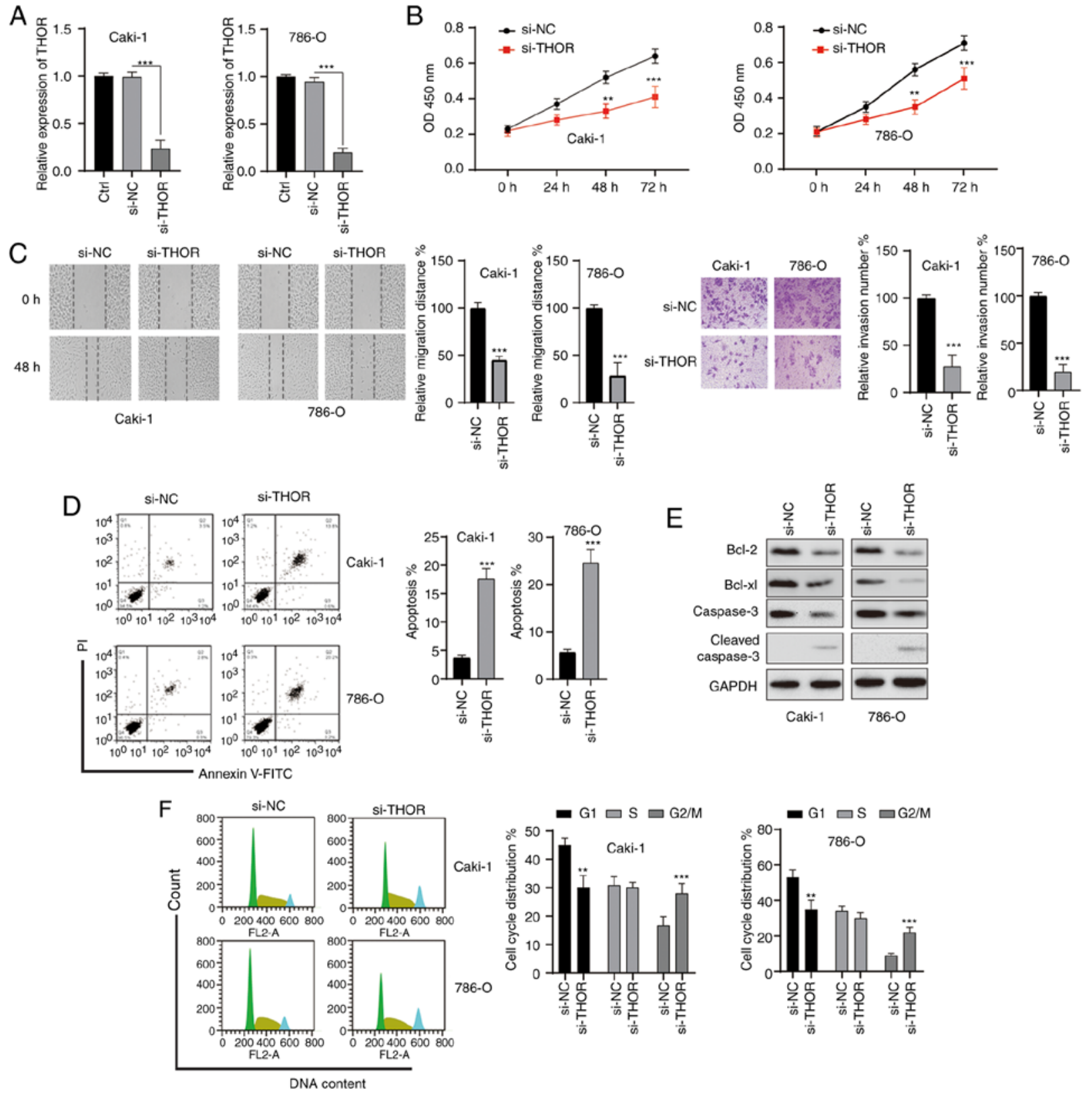

Figure 6. Silencing of THOR inhibits the tumorigenesis of renal cell carcinoma cells. (A) Cells were transfected as indicated for 24 h, and the expression of THOR was measured. (B) Cell viability was measured via an MTT assay after transfection. (C) Migration and invasion were measured after transfection. (D) Cellular apoptosis was measured after transfection. (E) Cellular lysates were subjected to western blotting analysis with the indicated antibodies after transfection. (F) Cell cycle distribution was analysed after transfection. The data are presented as the mean \pm SD of at least three independent experiments. ${ }^{* *} \mathrm{P}<0.01$ and ${ }^{* * *} \mathrm{P}<0.001$ vs. control group. si-, small interfering RNA; NC, negative control; THOR, testis associated oncogenic.

it was found that treatment with $\mathrm{CK}$ inhibited the expression levels of Bcl-2 and Bcl-xl, and increased the expression levels of Bax and cleaved caspase-3, which characterize the intrinsic pathway of apoptosis. Hence, these data suggested that $\mathrm{CK}$ induced apoptosis in RCC cells via the intrinsic pathway.

A number of studies have suggested that the accumulation of ROS plays a critical role in the antitumour effects of natural products, including ginsenosides (32). Consistent with a previous study, it was also observed that CK-treated RCC cells have an increased level of intracellular ROS compared with untreated cells (32). In addition, NAC, a ROS scavenger, significantly inhibited ROS generation and prevented the cell death caused by CK treatment. Moreover, the inhibitory effects of $\mathrm{CK}$ on the viability, migration and invasion of RCC cells were also reversed by NAC. These data further confirmed the role of ROS generation in the antitumour effects of CK.

lncRNAs are a group of RNAs that lack the ability to encode proteins and are $>200$ nucleotides in length. IncRNAs have been implicated in the processes of various human diseases, including cancer (33). To examine the possible role of lncRNAs in the antitumour effects of CK, the RT ${ }^{2}$ lncRNA PCR Array system was used in the present study. After treatment with $\mathrm{CK}$, the IncRNA that exhibited the greatest reduction, namely, THOR, was chosen for further investigation. THOR has been found to be dysregulated in various cancers, including RCC (34). Similar to a previous report, the present study also found that the downregulation of THOR led to the repression of tumorigenesis in RCC cells (34). Rescue 
A

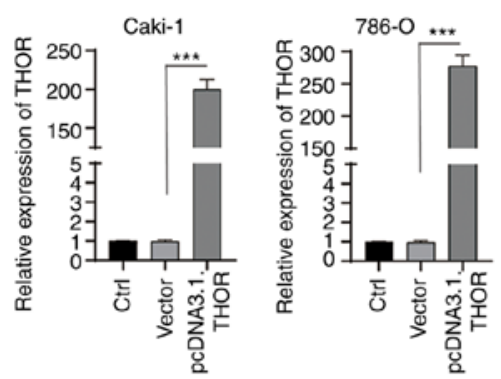

B

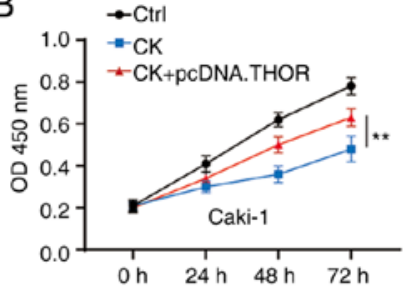

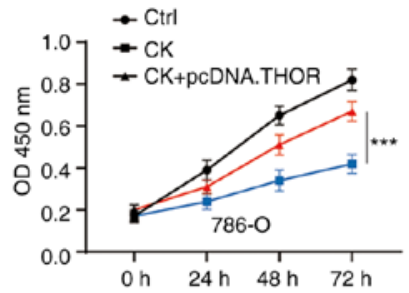

C
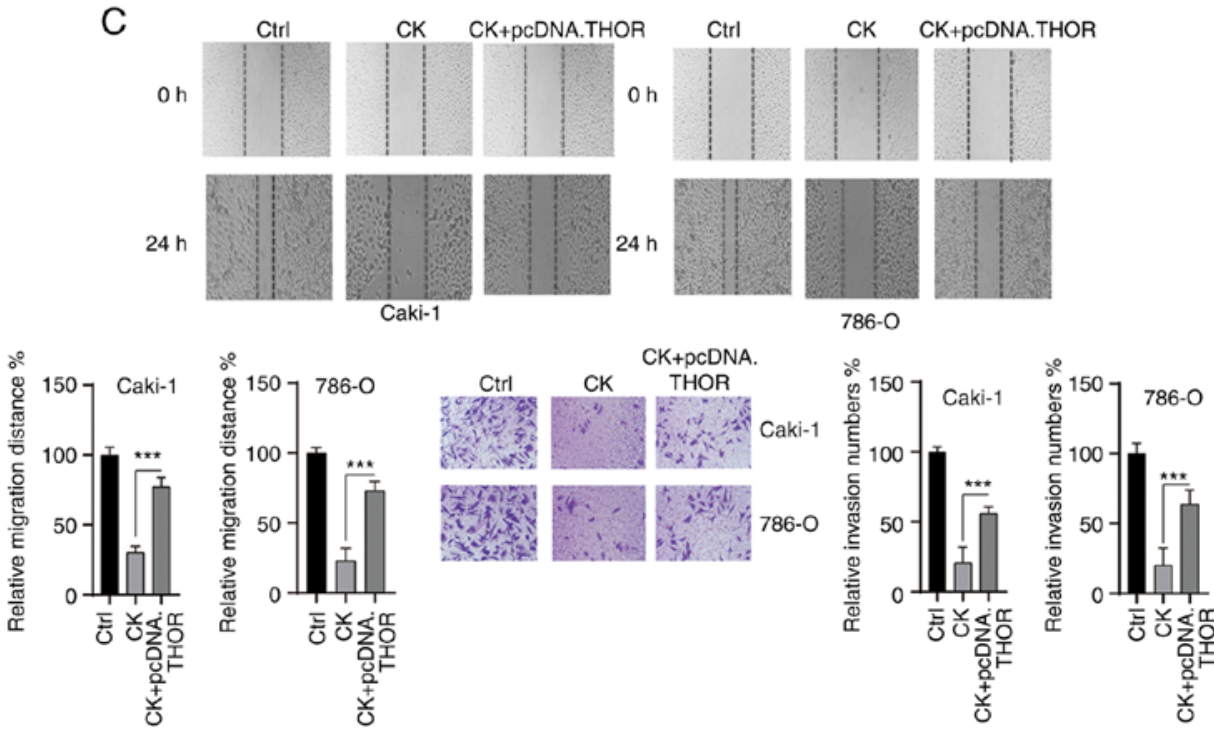

D
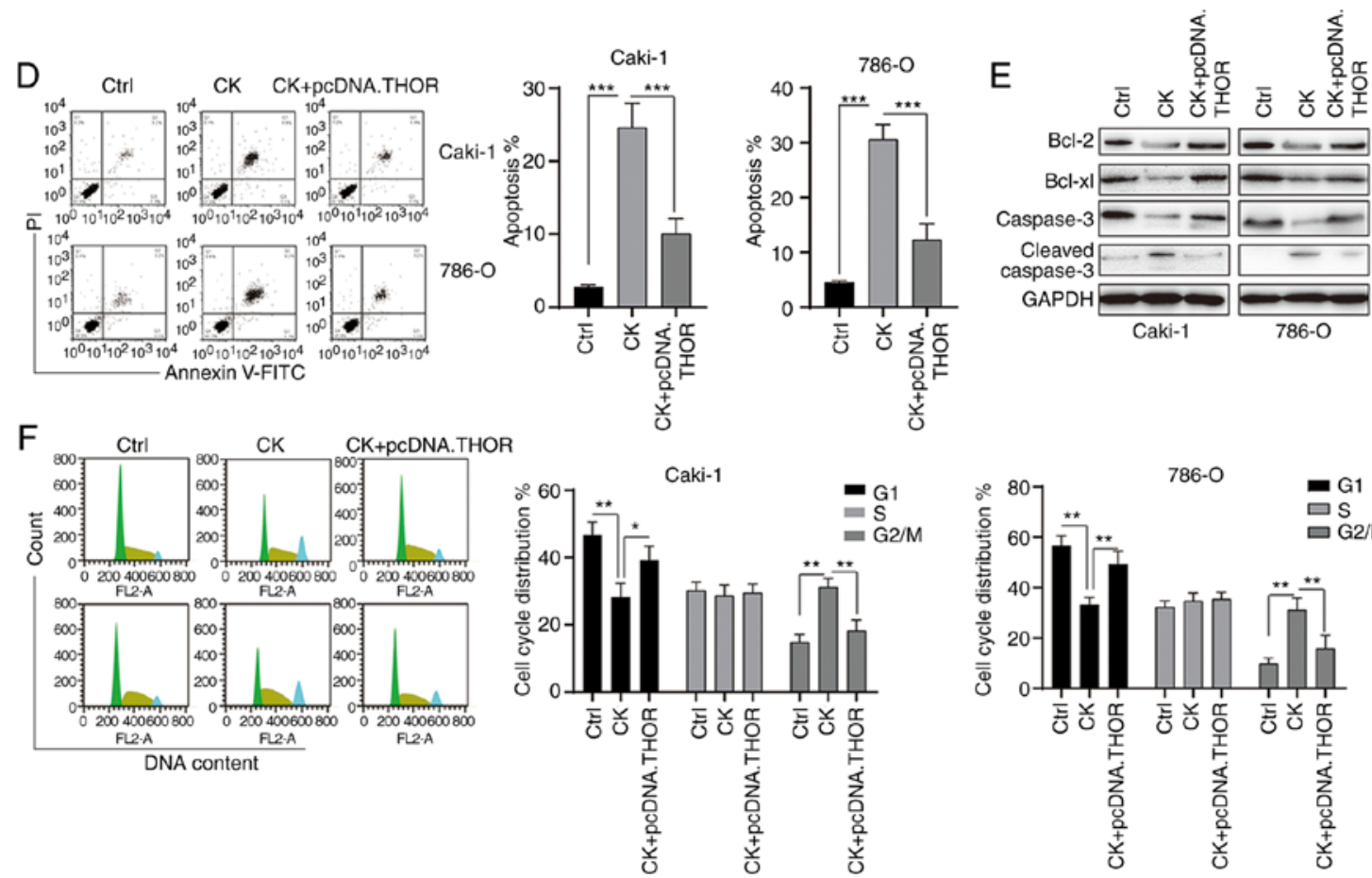

Figure 7. Upregulation of THOR inhibits the effects of CK on renal cell carcinoma cells. (A) Cells were transfected as indicated for $24 \mathrm{~h}$, and the expression of THOR was measured. (B) Cell viability was measured via an MTT assay after transfection. (C) Migration and invasion were measured after transfection. (D) Cellular apoptosis was measured after transfection. (E) Cellular lysates were subjected to western blotting analysis with the indicated antibodies after transfection. (F) Cell cycle distribution was analysed after transfection. The data are presented as the mean $\pm \mathrm{SD}$ of at least three independent experiments. ${ }^{*} \mathrm{P}<0.05,{ }^{* *} \mathrm{P}<0.01$ and ${ }^{* * *} \mathrm{P}<0.001$. CK, ginsenoside compound $\mathrm{K}$; THOR, testis associated oncogenic.

experiments showed that the antitumour effects of CK could be partially reversed by the overexpression of THOR. These findings indicated that CK exerted its effects by targeting
THOR. To the best of our knowledge, the present study is the first to show that lncRNAs are involved in the pharmacological activities of CK. 

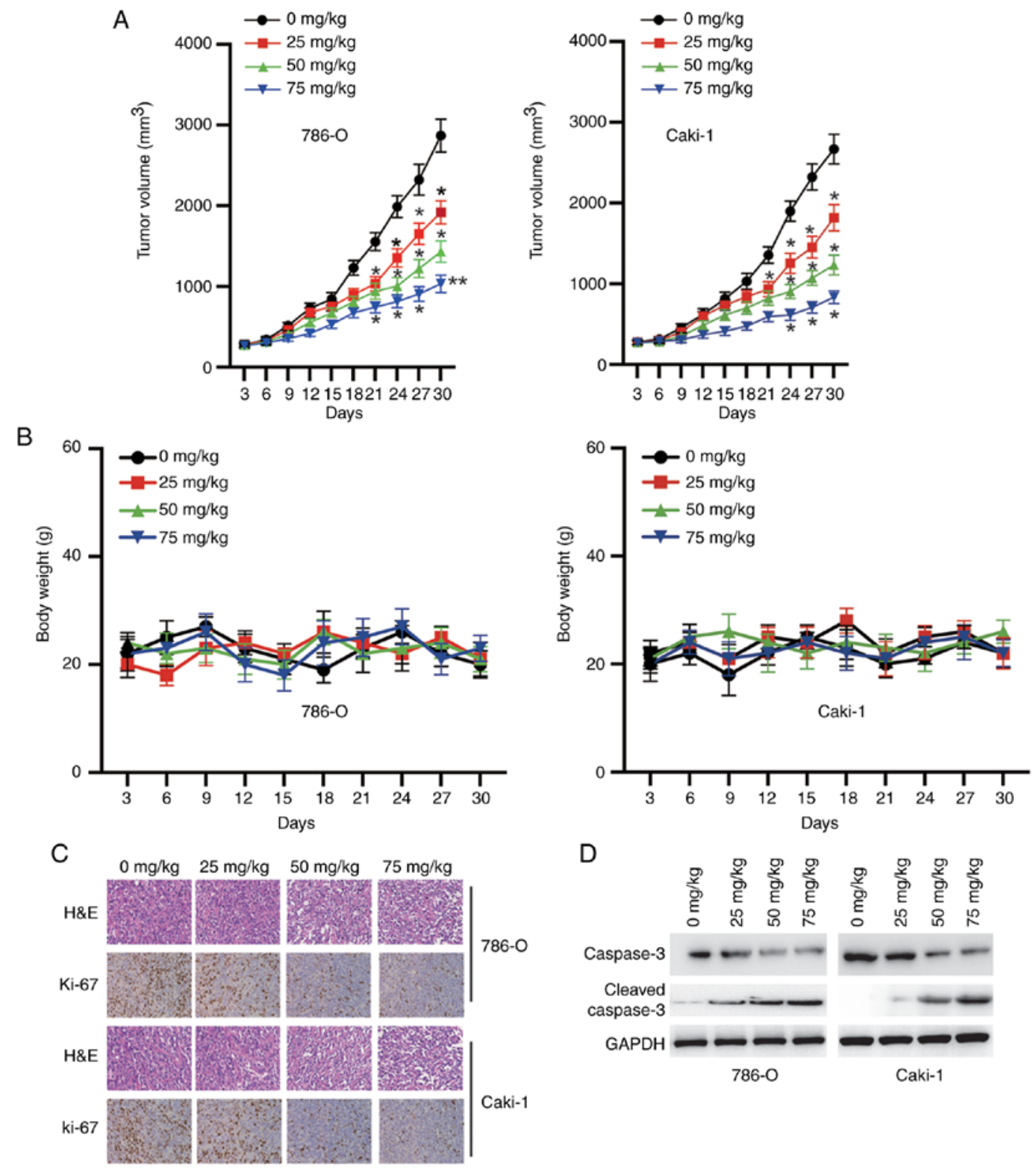

Figure 8. CK inhibits the growth of RCC cells in tumour xenografts. BALB/c mice were ectopically implanted with RCC cells, and when the tumour size reached $\sim 100 \mathrm{~mm}^{3}$, the mice were injected with CK (intraperitoneal) every 3 days for 30 days. (A) Effects of CK on tumour volume. (B) Effects of CK on mouse body weight. (C) H\&E staining and immunohistochemical analysis of changes in Ki-67 expression in the harvested tumours after different treatments as indicated. Representative images are shown (magnification, $x 40$ ). (D) Western blotting analysis of cleaved caspase-3 expression in tumours collected from different groups. " $\mathrm{P}<0.05$ and ${ }^{* *} \mathrm{P}<0.01$ vs. control group. CK, ginsenoside compound K; RCC, renal cell carcinoma; H\&E, haematoxylin and eosin.

There are, however, some limitations to this study. The mechanism by which CK decreased the expression of THOR in RCC cells remains unknown, and it would be of note to investigate the potential underlying mechanisms. In addition, it would also be useful to test the effects of $\mathrm{CK}$ alone or in combination with other agents against RCC in clinical trials.

In summary, the antitumour activity of $\mathrm{CK}$ were evaluated in RCC cells. The mechanistic investigations showed that CK inhibited EMT and induced apoptosis in a caspase-dependent manner in RCC cells. Furthermore, these findings showed that the generation of ROS and downregulation of THOR were also involved in the effects of CK on RCC cells. Collectively, these findings provided some novel insights into the functions of $\mathrm{CK}$, which may be used as a potential antitumour agent for the treatment of renal cancer.

\section{Acknowledgements}

The authors would like to acknowledge Dr Zhipeng Xu (Nanjing University; Nanjing, China) for his helpful suggestions during the present study.

\section{Funding}

The present study was supported by the Ningbo Natural Science Foundation (grant no. 2019A610259) and K.C. Wong Magna Fund of Ningbo University.

\section{Availability of data and materials}

The datasets used and/or analysed during the current study are available from the corresponding author on reasonable request. 


\section{Authors' contributions}

$\mathrm{SC}, \mathrm{HY}$ and FG made contributions to the acquisition and analysis of data. SC, SM and CL made contributions to the analysis of data. SC, CL and BX made contributions to the interpretation of data. YR and RY designed the study, and made contributions to the acquisition of funding and drafting of the manuscript. SC, HY and FG confirm the authenticity of all the raw data. All authors read and approved the final manuscript.

\section{Ethics approval and consent to participate}

The protocol was approved by the Institutional Animal Care and Use Committee of Zhongda Hospital, Southeast University (approval no. 2017043321; Nanjing, China). All experiments involving animals were conducted following the Guide for the Care and Use of Laboratory Animals published by the National Institutes of Health.

\section{Patient consent for publication}

Not applicable.

\section{Competing interests}

The authors declare that they have no competing interests.

\section{References}

1. Siegel RL, Miller KD and Jemal A: Cancer statistics, 2019. CA Cancer J Clin 69: 7-34, 2019.

2. Motzer RJ, Bander NH and Nanus DM: Renal-Cell carcinoma. N Engl J Med 335: 865-875, 1996.

3. Fontana F, Raimondi M, Marzagalli M, Di Domizio A and Limonta P: The emerging role of paraptosis in tumor cell biology: Perspectives for cancer prevention and therapy with natural compounds. Biochim Biophys Acta Rev Cancer 1873 188338, 2020.

4. Cho CW, Kim YC, Kang JH, Rhee YK, Choi SY, Kim KT, Lee YC and Hong HD: Characteristic study on the chemical components of Korean curved ginseng products. J Ginseng Res 37: 349-354, 2013.

5. Yang XD, Yang YY, Ouyang DS and Yang GP: A review of biotransformation and pharmacology of ginsenoside compound K. Fitoterapia 100: 208-220, 2015.

6. Gan XT and Karmazyn M: Cardioprotection by ginseng: Experimental and clinical evidence and underlying mechanisms. Can J Physiol Pharmacol 96: 859-868, 2018.

7. $\mathrm{Oh} \mathrm{J}$ and Kim JS: Compound $\mathrm{K}$ derived from ginseng: Neuroprotection and cognitive improvement. Food Funct 7 : 4506-4515, 2016.

8. Hasegawa H, Sung JH, Matsumiya S and Uchiyama M: Main ginseng saponin metabolites formed by intestinal bacteria. Planta Med 62: 453-457, 1996.

9. Kim H, Roh HS, Kim JE, Park SD, Park WH and Moon JY: Compound $\mathrm{K}$ attenuates stromal cell-derived growth factor 1 (SDF-1)-induced migration of C6 glioma cells. Nutr Res Pract 10 259-264, 2016.

10. Lee S, Kwon MC, Jang JP, Sohng JK and Jung HJ: The ginsenoside metabolite compound $\mathrm{K}$ inhibits growth, migration and stemness of glioblastoma cells. Int J Oncol 51: 414-424, 2017.

11. Shin DH, Leem DG, Shin JS, Kim JI, Kim KT, Choi SY, Lee MH, Choi JH and Lee KT: Compound K induced apoptosis via endoplasmic reticulum $\mathrm{Ca}^{2+}$ release through ryanodine receptor in human lung cancer cells. J Ginseng Res 42: 165-174, 2018.

12. Chen HF, Wu LX, Li XF, Zhu YC, Wang WX, Xu CW, Huang ZZ and Du KQ: Ginsenoside compound $\mathrm{K}$ inhibits growth of lung cancer cells via HIF-1 $\alpha$-mediated glucose metabolism. Cell Mol Biol (Noisy-le-grand) 65: 48-52, 2019.
13. Chen Y, Xu Y, Zhu Y and Li X: Anti-Cancer effects of ginsenoside compound $\mathrm{k}$ on pediatric acute myeloid leukemia cells. Cancer Cell Int 13: 24, 2013.

14. Law CK, Kwok HH, Poon PY, Lau CC, Jiang ZH, Tai WC, Hsiao WW, Mak NK, Yue PY and Wong RN: Ginsenoside compound $\mathrm{K}$ induces apoptosis in nasopharyngeal carcinoma cells via activation of apoptosis-inducing factor. Chin Med 9: 11, 2014.

15. Wang CZ, Du GJ, Zhang Z, Wen XD, Calway T, Zhen Z, Musch MW, Bissonnette M, Chang EB and Yuan CS: Ginsenoside compound $\mathrm{K}$, not Rb1, possesses potential chemopreventive activities in human colorectal cancer. Int J Oncol 40: 1970-1976, 2012.

16. Yu R, Yu BX, Chen JF, Lv XY, Yan ZJ, Cheng Y and Ma Q: Anti-Tumor effects of atractylenolide I on bladder cancer cells. J Exp Clin Cancer Res 35: 40, 2016.

17. Livak KJ and Schmittgen TD: Analysis of relative gene expression data using real-time quantitative PCR and the 2(-Delta Delta C(T)) method. Methods 25: 402-408, 2001.

18. Yates AD, Achuthan P, Akanni W, Allen J, Allen J, AlvarezJarreta J, Amode MR, Armean IM, Azov AG, Bennett R, et al: Ensemble 2020. Nucleic Acids Res 48: D682-D688, 2020.

19. Martinotti S and Ranzato E: Scratch wound healing assay. Methods Mol Biol 2109: 225-229, 2020.

20. American Association for Laboratory Animal Science: AALAS position statement on the humane care and use of laboratory animals. Com Med 4: 413, 2007.

21. Brodaczewska KK, Szczylik C, Fiedorowicz M, Porta C and Czarnecka AM: Choosing the right cell line for renal cell cancer research. Mol Cancer 15: 83, 2016.

22. Oh JM, Kim E and Chun S: Ginsenoside compound K induces ros-mediated apoptosis and autophagic inhibition in human neuroblastoma cells in vitro and in vivo. Int J Mol Sci 20: 4279, 2019.

23. Kim AD, Kang KA, Kim HS, Kim DH, Choi YH, Lee SJ, Kim HS and Hyun JW: A ginseng metabolite, compound K, induces autophagy and apoptosis via generation of reactive oxygen species and activation of JNK in human colon cancer cells. Cell Death Dis 4: e750, 2013.

24. Qi LW, Wang CZ, Du GJ, Zhang ZY, Calway T and Yuan CS: Metabolism of ginseng and its interactions with drugs. Curr Drug Metab 12: 818-822, 2011.

25. Paek IB, Moon Y, Kim J, Ji HY, Kim SA, Sohn DH, Kim JB and Lee HS: Pharmacokinetics of a ginseng saponin metabolite compound K in rats. Biopharm Drug Dispos 27: 39-45, 2006.

26. Zhang X, Zhang S, Sun Q, Jiao W, Yan Y and Zhang X: Compound $\mathrm{K}$ induces endoplasmic reticulum stress and apoptosis in human liver cancer cells by regulating STAT3. Molecules 19: 1482, 2018.

27. Yao H, Wan JY, Zeng J, Huang WH, Sava-Segal C, Li L, Niu X, Wang Q, Wang CZ and Yuan CS: Effects of compound K, an enteric microbiome metabolite of ginseng, in the treatment of inflammation associated colon cancer. Oncol Lett 15: 8339-8348, 2018.

28. Zhang K and Li Y: Effects of ginsenoside compound K combined with cisplatin on the proliferation, apoptosis and epithelial mesenchymal transition in MCF-7 cells of human breast cancer. Pharm Biol 54: 561-568, 2016.

29. Mani SA, Guo W, Liao MJ, Eaton EN, Ayyanan A, Zhou AY, Brooks M, Reinhard F, Zhang CC, Shipitsin M, et al: The epithelial-mesenchymal transition generates cells with properties of stem cells. Cell 133: 704-715, 2008

30. Piva F, Giulietti M, Santoni M, Occhipinti G, Scarpelli M, Lopez-Beltran A, Cheng L, Principato G and Montironi R: Epithelial to mesenchymal transition in renal cell carcinoma: Implications for cancer therapy. Mol Diagn Ther 20: 111-117, 2016.

31. Boice A and Bouchier-Hayes L: Targeting apoptotic caspases in cancer. Biochim Biophys Acta Mol Cell Res 1867: 118688, 2020.

32. Vallejo MJ, Salazar L and Grijalva M: Oxidative stress modulation and ROS-mediated toxicity in cancer: A review on in vitro models for plant-derived compounds. Oxid Med Cell Longev 2017: 4586068, 2017.

33. Huarte M: The emerging role of lncRNAs in cancer. Nat Med 21: 1253-1261, 2015

34. Ye XT, Huang H, Huang WP and Hu WL: LncRNA THOR promotes human renal cell carcinoma cell growth. Biochem Biophys Res Commun 501: 661-667, 2018.

This work is licensed under a Creative Commons Attribution-NonCommercial-NoDerivatives 4.0 International (CC BY-NC-ND 4.0) License. 